\title{
Commentary on "Higher versus Lower Amino Acid Intake in Parenteral Nutrition for Newborn Infants"
}

\author{
Nicholas D. Embleton ${ }^{a}$ b William McGuire ${ }^{c}$ \\ a Institute of Health and Society, Newcastle University, Newcastle upon Tyne, UK; ${ }^{b}$ Newcastle Neonatal Service, \\ Newcastle Hospitals NHS Foundation Trust, Newcastle upon Tyne, UK; ${ }^{c}$ Centre for Reviews and Dissemination, \\ University of York, York, UK
}

\section{Commentary}

Parenteral nutrition (PN) solutions consist of water, electrolytes, carbohydrate (dextrose), vitamins, micronutrients, and amino acids (AA) and are usually accompanied by intravenous lipid solutions. They were first given to newborn infants more than 50 years ago and are now considered a key component of neonatal intensive care. Whilst infants born at term with surgical complications or other reasons preventing enteral feeding need $\mathrm{PN}$, the commonest patient group receiving $\mathrm{PN}$ are preterm infants. In these infants, protein requirements can be more than twice those at term as nitrogen losses in the urine are around $1-1.5 \mathrm{~g} / \mathrm{kg}$ protein equivalent each day. Without early use of PN, very-preterm infants become malnourished. In many neonatal intensive care units, $\mathrm{PN}$ is routinely started on admission for most infants born $<32$ weeks' gestation and/or $<1,500 \mathrm{~g}$ birthweight. PN has important risks, including those associated with composition such as solution quality control, microbiological safety, solubility, and AA balance as well as risks associated with delivery such as use of central lines, sepsis, and line misplacement [1]. Most preterm infants take several days or weeks to achieve full milk feeds and so determining the optimal AA intake is an important issue in neonatal medicine [2].

AA requirements have been calculated using fetal nitrogen accretion as a reference. The so-called factorial method estimates that infants born at 24-28 weeks' gestation require an AA intake of around $3.5-4 \mathrm{~g} / \mathrm{kg} / \mathrm{day}$ if fetal protein accretion rates of approximately $2 \mathrm{~g} / \mathrm{kg}$ are to be enabled [3]. However, even relatively well preterm neonates are metabolically unstable, and hyperglycemia and hyperlipidemia are common. The ability to metabolize parenterally delivered AA may also be compromised, but there is no practical means of assessing this in clinical practice. The question this Cochrane Review aimed to determine is whether providing higher amounts of AA in the first few days improves important outcomes [4]. Osborn et al. [4] identified 32 studies of which 21 reported on clinical outcomes in preterm infants. Higher AA intakes (starting at $2-3 \mathrm{~g} / \mathrm{kg}$ and increasing to $3-4 \mathrm{~g} / \mathrm{kg}$, compared to lower doses at commencement or lower maximal amounts) had no impact on survival (Fig. 1),

\section{KARGER}

(c) 2019 S. Karger AG, Basel 


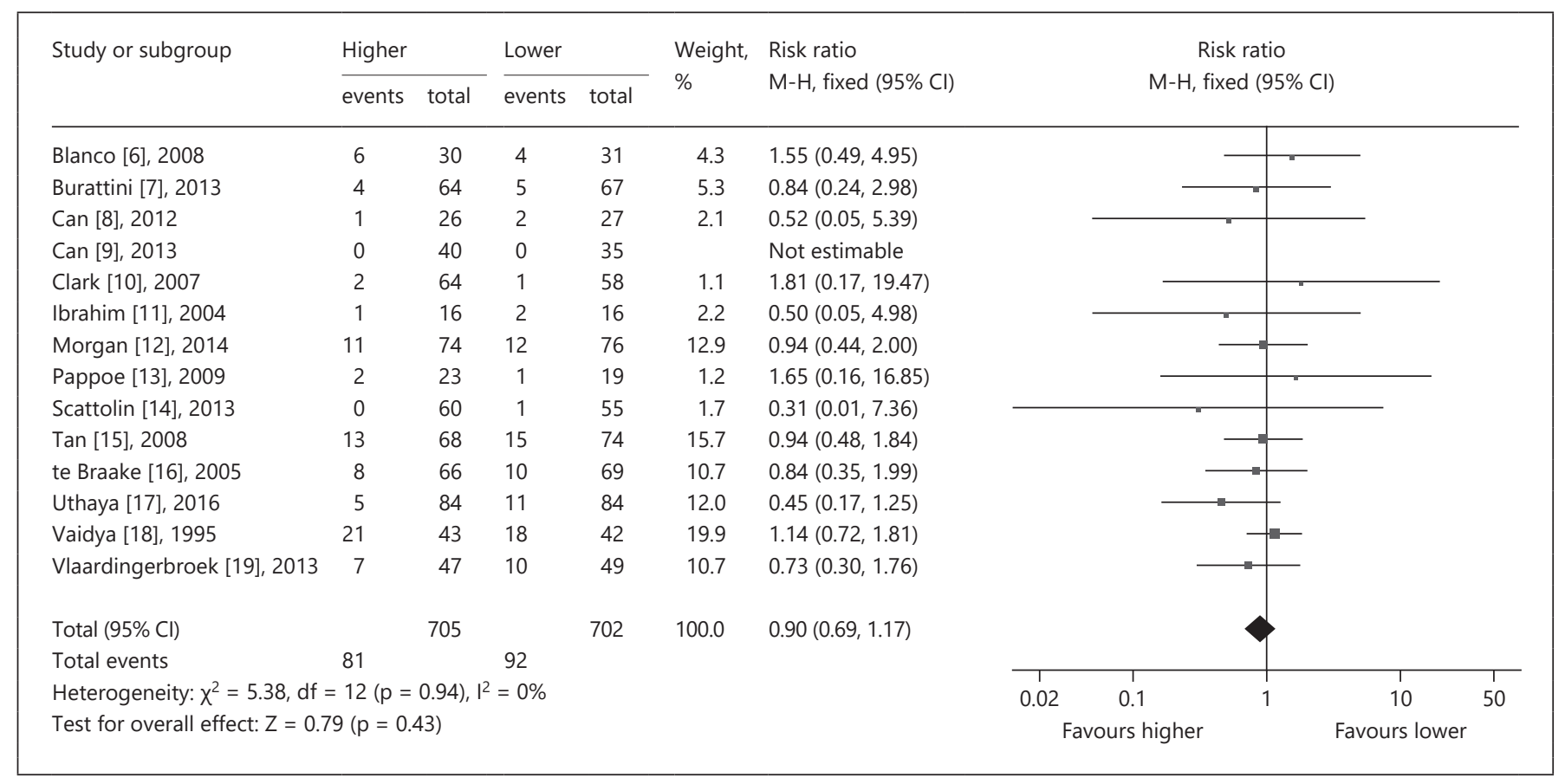

Fig. 1. Mortality to hospital discharge [6-19].

chronic lung disease, sepsis, necrotising enterocolitis, head circumference at hospital discharge (Fig. 2), brain injury, or later neurodevelopment but did demonstrate small benefits on weight gain, measures of protein accretion, and glucose control. An apparent reduction in retinopathy of prematurity was seen from meta-analyses of data from four studies, but the quality of evidence was very low, and an effect on severe retinopathy of prematurity was not observed.

It is not possible to determine the optimal regimen from the studies included in these meta-analyses. Higher intake may be beneficial or harmful. Populations of preterm infants vary markedly - it is plausible that a relatively stable 24-weeks'-gestation infant may benefit from an AA intake closer to $4 \mathrm{~g} / \mathrm{kg}$ while an unstable 30 -weeks'- gestation infant with severe sepsis may be harmed by an intake $>2 \mathrm{~g} / \mathrm{kg}$. We urgently need adequately powered trials with long-term functional outcomes to determine optimal AA intake [5].

\section{Acknowledgment}

Cochrane Neonatal Reviews are produced with support from Vermont Oxford Network, a worldwide collaboration of health professionals dedicated to providing evidence-based care of the highest quality for newborn infants and their families. Editorial support for Cochrane Neonatal has come from a UK National Institute of Health Research (NIHR) Cochrane Programme Grant $(16 / 114 / 03)$. 


\begin{tabular}{|c|c|c|c|c|c|c|c|c|c|c|}
\hline \multirow{2}{*}{ Study or subgroup } & \multicolumn{3}{|l|}{ Higher } & \multicolumn{3}{|l|}{ Lower } & \multirow{2}{*}{$\begin{array}{l}\text { Weight, } \\
\%\end{array}$} & \multirow{2}{*}{$\begin{array}{l}\text { Mean difference } \\
\text { IV, fixed ( } 95 \% \mathrm{Cl})\end{array}$} & \multirow{2}{*}{\multicolumn{2}{|c|}{$\begin{array}{l}\text { Mean difference } \\
\text { IV, fixed }(95 \% \mathrm{Cl})\end{array}$}} \\
\hline & mean & SD & total & mean & SD & total & & & & \\
\hline \multicolumn{11}{|l|}{ 1.16.1 At 1 month of age } \\
\hline Balasubramanian [20], 2013 & 28 & 1.48 & 60 & 29 & 2.22 & 63 & 23.1 & $-1.00(-1.66,-0.34)$ & & \\
\hline Can [8], 2012 & 31.3 & 0.8 & 25 & 30.8 & 1.1 & 25 & 35.8 & $0.50(-0.03,1.03)$ & & \\
\hline Clark [10], 2007 & 27.5 & 2.59 & 64 & 27 & 3.56 & 58 & 8.2 & $0.50(-0.61,1.61)$ & & - \\
\hline Morgan [12], 2014 & 27.1 & 1.6 & 66 & 26.5 & 1.7 & 69 & 32.9 & $0.60(0.04,1.16)$ & & 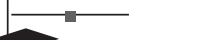 \\
\hline Subtotal $(95 \% \mathrm{Cl})$ & & & 215 & & & 215 & 100.0 & $0.19(-0.13,0.51)$ & & \\
\hline \multicolumn{11}{|c|}{ Heterogeneity: $\chi^{2}=16.02, d f=3(p=0.001), I^{2}=81 \%$} \\
\hline \multicolumn{11}{|c|}{ Test for overall effect: $Z=1.14(p=0.25)$} \\
\hline \multicolumn{11}{|l|}{ 1.16.2 At discharge } \\
\hline Bulbul [21], 2012 & 32.1 & 2.3 & 22 & 31.2 & 2.1 & 22 & 2.7 & $0.90(-0.40,2.20)$ & & \\
\hline Burattini [7], 2013 & 30.5 & 1.4 & 56 & 30.6 & 1.3 & 58 & 18.9 & $-0.10(-0.60,0.40)$ & & - \\
\hline Can [8], 2012 & 34.7 & 1.5 & 25 & 33.6 & 1.5 & 25 & 6.7 & $1.10(0.27,1.93)$ & & \\
\hline Morgan [12], 2014 & 31.6 & 1.3 & 63 & 31.1 & 1.5 & 63 & 19.4 & $0.50(0.01,0.99)$ & & \\
\hline Scattolin [14], 2013 & 30.85 & 1.34 & 60 & 30.71 & 1.94 & 55 & 12.3 & $0.14(-0.47,0.75)$ & & \\
\hline Tan [15], 2008 & 31.1 & 1.5 & 55 & 31.4 & 1.3 & 59 & 17.4 & $-0.30(-0.82,0.22)$ & & - \\
\hline te Braake [16], 2005 & 37.8 & 1.8 & 54 & 37.7 & 1.4 & 57 & 12.8 & $0.10(-0.50,0.70)$ & & \\
\hline Uthaya [17], 2016 & 35.0085 & 1.8098 & 71 & 35.6839 & 2.6349 & 62 & 7.7 & $-0.68(-1.45,0.10)$ & & \\
\hline Weiler [22], 2006 & 34.0077 & 2.1418 & 13 & 35.25 & 1.8384 & 14 & 2.0 & $-1.24(-2.75,0.27)$ & $\leftarrow$ & - \\
\hline Subtotal $(95 \% \mathrm{Cl})$ & & & 419 & & & 415 & 100.0 & $0.08(-0.14,0.29)$ & & \\
\hline \multicolumn{11}{|c|}{ Heterogeneity: $\chi^{2}=19.30, d f=8(p=0.01), 1^{2}=59 \%$} \\
\hline \multicolumn{11}{|c|}{ Test for overall effect: $Z=0.70(p=0.48)$} \\
\hline \multicolumn{11}{|l|}{ 1.16.3 Post discharge } \\
\hline Burattini [7], 2013 & 48.1 & 1.9 & 48 & 48.4 & 1.6 & 52 & 48.6 & $-0.30(-0.99,0.39)$ & - & - \\
\hline te Braake [16], 2005 & 48.4 & 1.9 & 54 & 48.2 & 1.7 & 57 & 51.4 & $0.20(-0.47,0.87)$ & & $\longrightarrow$ \\
\hline Subtotal $(95 \% \mathrm{Cl})$ & & & 102 & & & 109 & 100.0 & $-0.04(-0.52,0.44)$ & & \\
\hline \multicolumn{7}{|c|}{ Heterogeneity: $x^{2}=1.03, d f=1(p=0.31), l^{2}=3 \%$} & & & $\begin{array}{l}1 \\
-1\end{array}$ & $\begin{array}{l}1 \\
1\end{array}$ \\
\hline \multicolumn{7}{|c|}{ Test for overall effect: $Z=1.17(p=0.86)$} & & & \multicolumn{2}{|c|}{ Favours lower Favours higher } \\
\hline \multicolumn{11}{|c|}{ Test for subgroup differences: $\chi^{2}=0.65, d f=2(p=0.72), 1^{2}=0 \%$} \\
\hline
\end{tabular}

Fig. 2. Head circumference (cm) $[7,8,10,12,14-17,21,22]$.

\section{References}

1 Embleton ND, Morgan C, King C. Balancing the risks and benefits of parenteral nutrition for preterm infants: can we define the optimal composition? Arch Dis Child Fetal Neonatal Ed. 2015 Jan; 100(1):F72-5.

2 Embleton ND. Optimal protein and energy intakes in preterm infants. Early Hum Dev. 2007 Dec;83(12):831-7.

3 van Goudoever JB, Carnielli V, Darmaun D, Sainz de Pipaon M; ESPGHAN/ESPEN/ ESPR/CSPEN working group on pediatric parenteral nutrition. ESPGHAN/ESPEN/
ESPR guidelines on pediatric parenteral nutrition: amino acids. Clin Nutr. 2018 Dec;37(6 Pt B):2315-2323.

4 Osborn DA, Schindler T, Jones LJ, Sinn JK, Bolisetty S. Higher versus lower amino acid intake in parenteral nutrition for newborn infants. Cochrane Database Syst Rev. 2018 Mar; 3:CD005949.

5 Embleton ND, Van Den Akker CH. Early parenteral amino acid intakes in preterm babies: does NEON light the way? Arch Dis Child Fetal Neonatal Ed. 2018 Mar;103(2):F92-4.
6 Blanco CL, Falck A, Green BK, Cornell JE, Gong AK. Metabolic responses to early and high protein supplementation in a randomized trial evaluating the prevention of hyperkalemia in extremely low birth weight infants. J Pediatr. 2008;153(4):535-40.

7 Burattini I, Bellagamba MP, Spagnoli C, D’Ascenzo R, Mazzoni N, Peretti A, et al; Marche Neonatal Network. Targeting 2.5 versus $4 \mathrm{~g} / \mathrm{kg} /$ day of amino acids for extremely low birth weight infants: a randomized clinical trial. J Pediatr. 2013;163(5):1278-82. e1. 
8 Can E, Bulbul A, Uslu S, Comert S, Bolat F, Nuhoglu A. Effects of aggressive parenteral nutrition on growth and clinical outcome in preterm infants. Pediatr Int. 2012;54:869-74.

9 Can E, Bulbul A, Uslu S, Bolat F, Comert S, Nuhoglu A. Early aggressive parenteral nutrition induced high insulin-like growth factor 1 (IGF-1) and insulin-like growth factor binding protein 3 (IGFBP3) levels can prevent risk of retinopathy of prematurity. Iran J Pediatr. 2013;23(4):403-10.

10 Clark RH, Chace DH, Spitzer AR; Pediatrix Amino Acid Study Group. Effects of two different doses of amino acid supplementation on growth and blood amino acid levels in premature neonates admitted to the neonatal intensive care unit: a randomized, controlled trial. Pediatrics. 2007;120(6):1286-96.

11 Ibrahim HM, Jeroudi MA, Baier RJ, Dhanireddy R, Krouskop RW. Aggressive early total parental nutrition in low-birth-weight infants. J Perinatol. 2004;24:482-6.

12 Morgan C, McGowan P, Herwitker S, Hart AE, Turner MA. Postnatal head growth in preterm infants: a randomized controlled parenteral nutrition study. Pediatrics. 2014; 133:e120-8.
13 Pappoe TA, Wu S-Y, Pyati S. A randomized controlled trial comparing an aggressive and a conventional parenteral nutrition regimen in very low birth weight infants. J Neonatal Perinatal Med. 2009;2(3):149-56.

14 Scattolin S, Gaio P, Betto M, Palatron S, De Terlizzi F, Intini F, et al. Parenteral amino acid intakes: possible influences of higher intakes on growth and bone status in preterm infants. J Perinatol. 2013;33(1):33-9.

15 Tan MJ, Cooke RW. Improving head growth in very preterm infants - a randomised controlled trial I: neonatal outcomes. Arch Dis Child Fetal Neonatal Ed. 2008;93(5):F337-41.

16 te Braake FW, van den Akker $\mathrm{CH}$, Wattimena DJ, Huijmans JG, van Goudoever JB. Amino acid administration to premature infants directly after birth. J Pediatr. 2005;147(4):45761.

17 Uthaya S, Liu X, Babalis D, Dore CJ, Warwick J, Bell J, et al. Nutritional evaluation and optimisation in neonates: a randomized, doubleblind controlled trial of amino acid regimen and intravenous lipid composition in preterm parenteral nutrition. Am J Clin Nutr. 2016; 103:1443-52. [CRSREF: 7693105]
18 Vaidya UV, Bhave SA, Pandit AN. Parenteral nutrition $(\mathrm{PN})$ in the management of very low birth weight (VLBW) babies - a randomized controlled trial. Indian Pediatr. 1995;32(2): 165-70.

19 Vlaardingerbroek H, Vermeulen MJ, Rook D, van den Akker CH, Dorst K, Wattimena JL, et al. Safety and efficacy of early parenteral lipid and high-dose amino acid administration to very low birth weight infants. J Pediatr. 2013; 163(3):638-44. e1-5.

20 Balasubramanian H, Nanavati RN, Kabra NS Effect of two different doses of parenteral amino acid supplementation on postnatal growth of very low birth weight neonates - a randomized controlled trial. Indian Pediatr. 2013;50(12):1131-6.

21 Bulbul A, Okan F, Bulbul L, Nuhoglu A. Effect of low versus high early parenteral nutrition on plasma amino acid profiles in very low birth-weight infants. J Matern Fetal Neonatal Med. 2012;25(6):770-6.

22 Weiler HA, Fitzpatrick-Wong SC, Schellenberg JM, Fair DE, McCloy UR, Veitch RR, et al. Minimal enteral feeding within $3 \mathrm{~d}$ of birth in prematurely born infants with birth weight $<$ or $=1,200 \mathrm{~g}$ improves bone mass by term age. Am J Clin Nutr. 2006;83(1):155-62.

\section{Cochrane Abstract}

Background: Sick newborn and preterm infants frequently are not able to be fed enterally, necessitating parenteral fluid and nutrition. Potential benefits of higher parenteral amino acid (AA) intake for improved nitrogen balance, growth, and infant health may be outweighed by the infant's ability to utilise high intake of parenteral AA, especially in the days after birth. Objectives: The primary objective is to determine whether higher versus lower intake of parenteral AA is associated with improved growth and disabilityfree survival in newborn infants receiving parenteral nutrition. Secondary objectives include determining whether (a) higher versus lower starting or initial intake of AAs is associated with improved growth and disability-free survival without side effects; (b) higher versus lower intake of AAs at maximal intake is associated with improved growth and disability-free survival without side effects; and (c) increased AA intake should replace non-protein energy intake (glucose and lipid), should be added to non-protein energy intake, or should be provided simultaneously with non- protein energy intake. We conducted subgroup analyses to look for any differences in the effects of higher versus lower intake of AAs according to gestational age, birth weight, age at commencement, and condition of the infant, or concomitant increases in fluid intake. Search Methods: We used the standard search strategy of the Cochrane Neonatal Review Group to search the Cochrane Central Register of Controlled Trials (June 2, 2017), MEDLINE (1966 to June 2, 2017), Embase (1980 to June 2, 2017), and the Cumulative Index to Nursing and Allied Health Literature (CINAHL) (1982 to June 2, 2017). We also searched clinical trial databases, conference proceedings, and citations of articles. Selection Criteria: We included randomised controlled trials of higher versus lower intake of AAs as parenteral nutrition in newborn infants. Comparisons of higher intake at commencement, at maximal intake, and at both commencement and maximal intake were performed. Data Collection and Analysis: Two review authors independently selected trials, assessed trial quality, and extracted data from included 
studies. We performed fixed-effect analyses and expressed treatment effects as mean difference (MD), risk ratio (RR), and risk difference (RD) with $95 \%$ confidence intervals $(\mathrm{Cls})$ and assessed the quality of evidence using the GRADE approach. Main Results: Thirty-two studies were eligible for inclusion. Six were short-term biochemical tolerance studies, one was in infants at $>35$ weeks' gestation, one in term surgical newborn infants, and three yielding no usable data. The 21 remaining studies reported clinical outcomes in very-preterm or low-birth-weight infants for inclusion in the meta-analysis for this review. Higher AA intake had no effect on mortality before hospital discharge (typical RR 0.90, 95\% Cl 0.69-1.17; participants $=1,407$; studies $=14 ; I^{2}=0 \%$; quality of evidence: low). Evidence was insufficient to show an effect on neurodevelopment and suggest no reported benefit (quality of evidence: very low). Higher AA intake was associated with a reduction in postnatal growth failure ( $<10$ th centile) at discharge (typical RR $0.74,95 \% \mathrm{Cl} 0.56-0.97$; participants $=203$; studies $=3$; $\mathrm{I}^{2}=22 \%$; typical RD $0.15,95 \% \mathrm{Cl} 0.27-0.02$; number needed to treat for an additional beneficial outcome 7, 95\% Cl 4-50; quality of evidence: very low). Subgroup analyses found reduced postnatal growth failure in infants who commenced on high AA intake ( $>2$ to $\leq 3 \mathrm{~g} / \mathrm{kg} /$ day); who had increased $A A$ and non-protein caloric intake; who commenced on intake at the age of $<24 \mathrm{~h}$; and who had early lipid infusion. Higher AA intake was associated with a reduction in days needed to regain birth weight (MD 1.14, 95\% Cl 1.730.56 ; participants $=950$; studies $\left.=13 ; 1^{2}=77 \%\right)$. The data show varying effects on growth parameters and no consistent effects on anthropometric $z$ scores at any time point, as well as increased growth in head circumference at discharge (MD $0.09 \mathrm{~cm} /$ week, $95 \% \mathrm{Cl}$ $0.06-0.13$; participants $=315$; studies $=4 ; \mathrm{I}^{2}=90 \%$; quality of evidence: very low). Higher AA intake was not associated with effects on days to full enteral feeds, late-onset sepsis, necrotising enterocolitis, chronic lung disease, any or severe intraventricular haemorrhage, or periventricular leukomalacia. The data show a reduction in retinopathy of prematurity (typical RR 0.44, 95\% Cl 0.21-0.93; participants $=269$; studies $=4 ; I^{2}=31 \%$; quality of evidence: very low) but no difference in severe retinopathy of prematurity. Higher AA intake was associated with an increase in positive protein balance and nitrogen balance. Potential biochemical intolerances were reported, including the risk of abnormal blood urea nitrogen (typical RR 2.77, 95\% Cl 2.13-3.61; participants $=688$; studies $=7$; $\mathrm{I}^{2}=6 \%$; typical RD $0.26,95 \% \mathrm{Cl} 0.20-0.32$; number needed to treat for an additional harmful outcome 4; $95 \% \mathrm{Cl} 3$ to 5; quality of evidence: high). Higher AA intake in parenteral nutrition was associated with a reduction in hyperglycaemia ( $>8.3 \mathrm{mmol} / \mathrm{L}$ ) (typical RR $0.69,95 \% \mathrm{Cl} 0.49-0.96$; participants $=505$; studies $=5$; $\left.1^{2}=68 \%\right)$, although the incidence of hyperglycaemia treated with insulin was not different. Reviewers' Conclusions: Low-quality evidence suggests that higher AA intake in parenteral nutrition does not affect mortality. Very-low-quality evidence suggests that higher AA intake reduces the incidence of postnatal growth failure. Evidence was insufficient to show an effect on neurodevelopment. Very-low-quality evidence suggests that higher AA intake reduces retinopathy of prematurity but not severe retinopathy of prematurity. Higher AA intake was associated with potentially adverse biochemical effects resulting from excess amino acid load, including azotaemia. Adequately powered trials in very-preterm infants are required to determine the optimal intake of $A A$ and effects of caloric balance in parenteral nutrition on the brain and on neurodevelopment [see Ref. 4]. 